\title{
Delaminated Rotator Cuff Tear: Concurrent Concept and Treatment
}

\author{
Jung-Han Kim, Soo-Hwan Jung \\ Department of Orthopedic Surgery, Inje University Busan Paik Hospital, Inje University College of Medicine, Busan, Korea
}

\begin{abstract}
Delaminated rotator cuff tear pertains to the horizontal split of the tendon substance. As reported previously, the presence of a delaminated tear and incidence of delaminated rotator cuff tear ranges from $38 \%$ to $92 \%$. The different strain intensities applied across the rotator cuff tendon, and the shear stress between the bursal and articular layers seem to play a role in its pathogenesis. In a delaminated rotator cuff tear, the degree and direction of retraction between two layers differ, with accompanying intrasubstance cleavage. A surgeon therefore needs to consider and carefully evaluate the tear characteristics when repairing delaminated rotator cuff tear. Delaminated rotator cuff tear is considered to be a poor prognostic factor after rotator cuff repair, but numerous surgical repair techniques have been introduced and applied to resolve this problem. Recent literature has reported good clinical outcomes after delaminated rotator cuff repair. (Clin Shoulder Elbow 2019;22(3):159-170)
\end{abstract}

Key Words: Delaminated; Rotator cuff tear; Shoulder; Arthroscopic repair; Prognostic factor

\section{Introduction}

Rotator cuff tear is a common shoulder lesion afflicting pain and disability to the patient. Hence, the main purpose of repairing a torn rotator cuff is to improve quality of life of the patient by decreasing the pain, and improving shoulder function. Literatures on arthroscopic rotator cuff repair have reported re-tear rates between $11.4 \%$ and $94 \%$, which correlates with a poor surgical outcome. ${ }^{1-3)}$ To increase healing and clinical outcome, the surgeon needs to consider multiple factors such as patient age, tear size, fatty degeneration of cuff tissue, tendon retraction, repair construct and rehabilitation. ${ }^{4,5)}$

Failure to address the tear configuration and pattern in rotator cuff repair may be one of the reasons for failure to maintain the structural integrity after rotator cuff repair.

Delaminated rotator cuff tear is usually described as a horizontal split of the tendon substance, and the presence of a delaminated tear ${ }^{6)}$ is considered a negative prognostic factor in functional and morphologic results after rotator cuff repairs. ${ }^{7,8)}$ However, delaminated rotator cuff tear has received little at- tention in previous literature. Moreover, due to varying and ambiguous definitions of delamination in rotator cuff tear, and different diagnostic approaches used (radiologic method, arthroscopic and open examination), the reported incidence varies according to researchers. ${ }^{6,8,9-11)}$ Since maximizing the contact area and creating strong constructs are the recognized surgical goals when repairing a rotator cuff tear, precise evaluation of delamination is very vital. However, delamination is easily missed in preoperative investigations and can be overlooked at surgery if not specifically sought, because the deep layer is more retracted. Moreover, there are very few studies describing the characteristics of delaminated tear and its pattern. ${ }^{9,12-14)}$ Although delaminated rotator cuff tear is considered a negative prognostic factor in cuff healing, ${ }^{7,8)}$ many surgical techniques have been introduced to improve the outcomes. ${ }^{15-20)}$ However, the optimal surgical method remains controversial. This review was therefore undertaken to summarize the definition, determine the incidence, pathogenesis, characteristics and pattern of delaminated rotator cuff tear, and to review the surgical techniques available and their clinical outcomes.

Received February 15, 2019. Revised March 16, 2019. Accepted May 6, 2019.

Correspondence to: Soo-Hwan Jung

Department of Orthopedic Surgery, Inje University Busan Paik Hospital, Inje University College of Medicine, 75 Bokji-ro, Busanjin-gu, Busan 47392, Korea

Tel: +82-51-890-6129, Fax: +82-51-892-6619, E-mail: osoohwanj@gmail.com, ORCID: https://orcid.org/0000-0002-3847-3642

Review article does not need an IRB approval.

Financial support: None. Conflict of interests: None. 


\section{Definition and Incidence}

A delaminated rotator cuff tear is a form of degeneration within the tendon; it generally refers to a horizontal tear occurring between rotator cuff layers. ${ }^{11,21-23)}$ Literature has various definitions of a delaminated rotator cuff tear. Ellman ${ }^{23)}$ first described laminated as the horizontal component of a partial tear. Sonnabend et al. ${ }^{11,24)}$ defined delaminated tear as a horizontal, partial thickness split of tendon midsubstance. Boileau et al. ${ }^{8)}$ defined delaminated rotator cuff tear as tears that extended anteriorly or posteriorly, without disruption of the tendinous insertion. Resn$\mathrm{ick}^{22)}$ defined delamination of cuff as horizontal intrasubstance tear and retraction of a portion of the intratendinous fiber.

Edge fraying or cleavage greater than or equal to $5 \mathrm{~mm}$ was the definition reported by MacDougal and Todhunter, ${ }^{10)}$ whereas Han et al. ${ }^{6}$ defined it as a significant horizontal intratendinous tear. Gwak et al. ${ }^{9)}$ classified them as full thickness and partial thickness delaminated rotator cuff tear, and defined delamination as a distinguishable gap between the articular and bursal surface and interstitial horizontal splitting.

Radiologically, Lee and Lee ${ }^{25}$ ) defined delaminated tear as the linear pooling of contrast within long axis of the tendon. Walz et al. ${ }^{26)}$ defined it as a horizontal retraction of either bursal or articular surface (anterior or interstitial horizontal splitting). Due to these many different definitions by authors, previous studies report the incidence of delaminated rotator cuff tears ranging from $38 \%$ to $92 \%{ }^{6-8,10,11)}$ In addition, as arthroscopic techniques and equipment as well as knowledge about rotator cuff tendon develop, recent years has seen an increase in incidence: Sonnabend and Watson, ${ }^{11)} 38 \%$; Boileau et al., ${ }^{8} 51 \%$; Flurin et al, ${ }^{7}$ 57\%; MacDougal and Todhunter, ${ }^{10)} 71 \%$; Han et al., ${ }^{6}$ 92\%. The substantial variation in the incidence of delamination might be due to the various definitions of delaminated tears among the studies, and to the indifference of surgeons to observe for presence of delamination.

\section{Pathogenesis}

Until now, the precise pathophysiology of delaminated rotator cuff tear has not been fully delineated. Several researchers have suggested that the biomechanical properties and strain patterns characteristic of the rotator cuff tendon may be related with delamination of the rotator cuff tendon. Many studies have emphasized the different strain levels applied across the rotator cuff tendon. ${ }^{27-30)}$ Reilly et al. ${ }^{27)}$ reported that a statistically significant increase of the strain on the articular side and a decrease on the bursal side were observed during abduction to 120 degree. Moreover, a high level of stress concentration was found on the articular surface at the cuff insertion area and at the rotator cuff tear site, extending proximally. ${ }^{28)}$ Nakajima et al. ${ }^{30)}$ showed that the histology and biomechanical properties of the bursal and articular tendon layers are different. They reported the articular layer as being more vulnerable to a tensile load, whereas the bursal layer provided greater deformation and tensile strength. Biomechanical displacement controlled studies have shown fibers of the superficial layer to have maximum tension at 90 degree of glenohumeral abduction, whereas the deep layer has maximum tension at 22 degree of glenohumeral abduction. This difference of strain creates a shearing force between the 2 layers, which results in a delaminating tear, indicating that shear stress between the bursal and articular layers seems to play a role in the pathogenesis. Dissimilar stress between two layers of the rotator cuff and local ischemia related to hypertrophic changes in the small arteries of the rotator cuff have been postulated as causes of delaminated tears. ${ }^{24)}$ In a biomechanical study, Huang et al. ${ }^{31)}$ showed that the deep layer of the posterosuperior cuff disrupts first, subsequently involves the superficial layer, and finally the infraspinatus. On ultrasound speckle tracking imaging, Kim et al. ${ }^{29)}$ reported observing different strain levels applied between the superficial and deep regions within the intact supraspinatus tendon. They suggested that the different strain patterns occurring with isometric or isotonic motions might each be aggravated during daily activities.

Multi-layered histologic anatomy of the rotator cuff tendon is possibly related with delamination. Clark and Harryman ${ }^{32)}$ noted that rotator cuffs at the anterior part of the greater tubercle of the humerus are closely intermingled, and comprise the musculotendinous part of the rotator cuff, the articular capsule, and the coracohumeral ligament. Differences in connections between the layers according to anatomic features (anterior and posterior part) might be one reason for delamination. In their histologic and immunochemical study, Sonnabend et al. ${ }^{24)}$ reported that the lamination split generally occurs between layers of differing collagen fiber orientation, although several specimens showed that at least part of the split occurs within a single layer. Another study proposed that delamination reflects chronicity of an underlying pathologic condition. Chronic degenerative change within the tendon might therefore be related to the development of delamination.

\section{Characteristics of Delaminated Rotator Cuff Tear}

\section{Clinical Characteristics}

The relationship of age and sex with rotator cuff tear is controversial. Matsuki et al. ${ }^{33)}$ noted that the demographic characteristics of delaminated rotator cuff tear incidence are a high percentage in the elderly and in women, while MacDougal and Todhunter ${ }^{10)}$ reported that age and sex are not related with the occurrence of delaminated rotator cuff tear. Iwashita et al. ${ }^{12)}$ reported that the percentage of delaminated rotator cuff tear showed no significant relation with age, sex, condition duration, 
injury, or diabetes.

\section{Histologic Characteristics}

Few studies have reported the histopathologic and immunohistochemical properties of delaminated rotator cuff tear. Sonnabend et al. ${ }^{24)}$ reported their results on 17 patients $(11$ male and 6 female, mean age 58.5 years). They suggested that careful morphologic examination revealed no regular pattern, but five characteristics were observed: 1 ) the lamination split usually occurs between layers with different collagen fiber orientation, 2) areas of necrosis were common near both the margins and at apex of the lamina split, 3) numerous blood vessels with accompanying fibroblast were frequently found at the margin of the areas of necrosis, 4) endarteritis obliterans was observed to varying degrees, and 5) a synovial-like lining of the lamination split was found.

They reported that hypertrophic changes in most small arteries and arterioles, and subsequent narrowing of vascular lumen, lead to decreased vascularity and oxygen tension, which further contributes to local ischemia and development of cuff tear and delamination. However, they also suggested that it is unclear whether these vascular changes precede and contribute to the lamination, or are a response to the chronic condition of cuff tear and its delamination. Furthermore, the synovial lining of lamination is clinically significant since it prevents the layers from healing together. Hence, the surface of the laminated layer should be carefully curetted before suture to remove any synovial lining, thereby facilitating the healing process.

\section{Morphologic Characteristics}

Difference of retraction between the superficial bursal layer and the deeper articular layer has been reported. Matsuki et al. $^{33)}$ reported that most delamination occurs proximally and posteriorly. In addition, numerous other works of literature reported that the deeper articular layer is usually more retracted than the superficial bursal layer. ${ }^{6,9,13-15,20,34,35)}$ In their study using magnetic resonance imaging (MRI) evaluation, Gwak et al. ${ }^{9)}$ reported that the mean gap between the articular and bursal layer was $10.3 \pm 4.9 \mathrm{~mm}$ in the full thickness delaminated tear, and $9.1 \pm 5.0 \mathrm{~mm}$ in the partial thickness delaminated tear, indicating that the deeper layer retracted more medially compared to the superficial layer, and also many cases exceed the mean value determined. This finding has some clinical relevance. Han et al. ${ }^{6}{ }^{6}$ noted that the articular surface layer could be missed since it is more retracted than the bursal surface layer, and suggested that posterior delamination is detected differently according to the portal used for access (Fig. 1). In addition, difference of retraction between the layers may lead to tension mismatch while repairing a delaminated rotator cuff tendon, and affect appropriate selection of the operative repair technique. In their comparison study between delaminated and non-delaminated rotator cuff tear patients, Kim et al. ${ }^{36)}$ reported that partially healed defects were statistically common in delaminated rotator cuff tear patients after surgery.

Numerous studies report the presence of intrasubstance cleavage in delaminated rotator cuff tears. ${ }^{9,24,37)}$ This lesion may be the area that Sonnabend et al. ${ }^{24)}$ described as the synovial lining. Gwak et al. ${ }^{9)}$ reported that the intrasubstance cleavage extends more medially from the margin of the retracted layer. They insisted that part of the intrasubstance cleavage may not be sealed properly after rotator cuff repair, and their study determined that $74.3 \%$ of anatomically healed cases reveal remaining intrasubstance cleavage after bone to tendon healing.
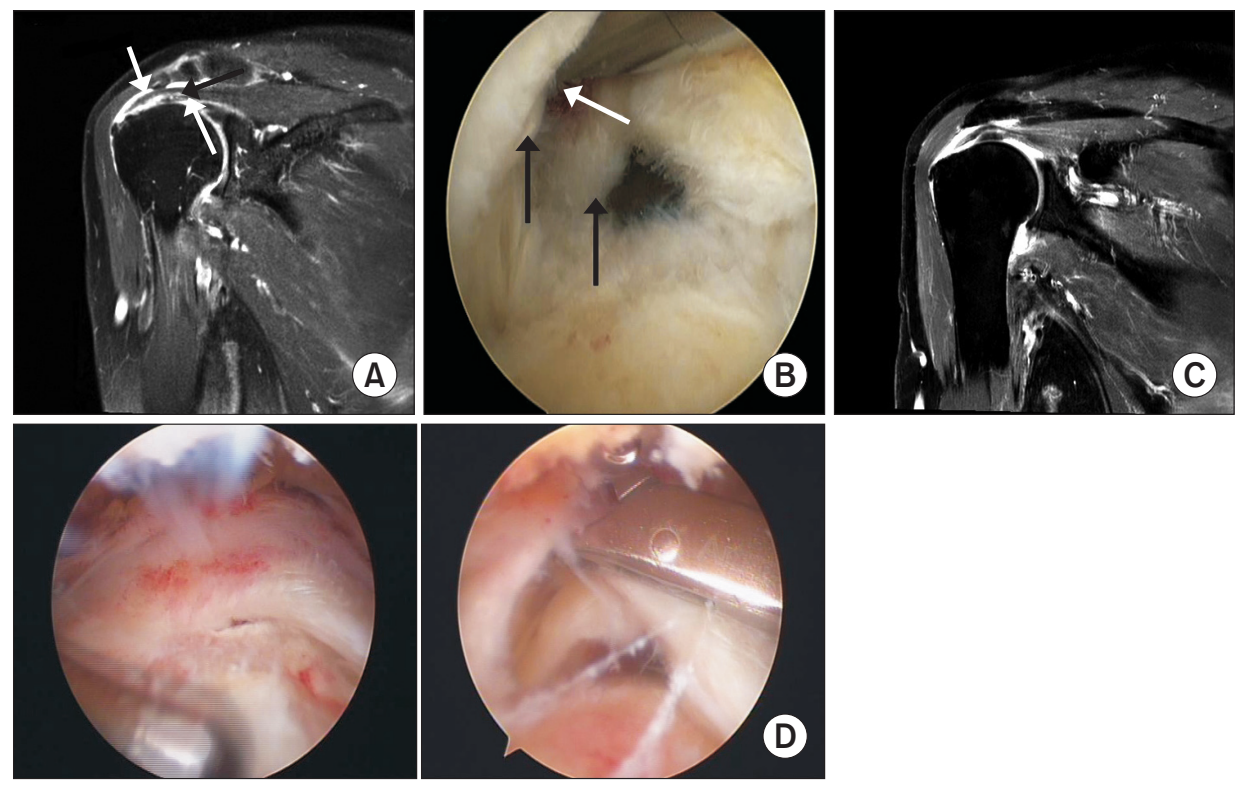

Fig. 1. Preoperative MRI and intraoperative arthroscopic findings of full-thickness delaminated rotator cuff tear. (A) Coronal oblique MRI showed horizontally retracted tear of both the articular and bursal surfaces of the tendon (white arrows) with intrasubstance cleavage (black arrow). (B) Intraoperative arthroscopy showed horizontally retraced tear of both layers (black arrows) and interstitial horizontal splitting (white arrow). (C) Delaminated rotator cuff tears in the coronal oblique magnetic resonance image. (D) Typical delaminated rotator cuff tears in the arthroscopic findings representing bursal and articular layers of the delaminated tears. 


\section{Tear Pattern}

Tanaka et al. ${ }^{34)}$ studied the location and thickness of delamination rotator cuff tears by examining surgical records and reporting tear pattern. They suggested that larger the size of the rotator cuff tear, greater was the frequency of delamination being limited to the posterior part. Matsuki et al. ${ }^{33)}$ also reported that delamination frequently occurred in the posterior part of the torn site rather than the anterior site. Han et al. ${ }^{6}$ reported $88 \%$ cases develop delamination in the posterior region of the torn site, and $42 \%$ cases develop in the anterior area. Iwashita et al. ${ }^{12)}$ found significantly higher incidence of delaminated rotator cuff tear in patients with more than 2 tendon involvement, and in patients with large sized tear. There is clear explanation for the above findings. Authors speculated that due to the differences in anatomic features, the connections between layers seem to be tighter at the anterior region of the tear than the posterior, and suggest that it might be the most plausible reason that delamination was more frequent in the posterior than in the anterior part. In addition, the finding that delamination is frequently found in large sized tears might imply that delamination is a progressive lesion, and is caused by tears in the superficial and deep layers

Table 1. Treatment-based Classification System for Posterior Delamination in Rotator Cuff Repair ${ }^{6}$

\begin{tabular}{|c|c|c|}
\hline Type & Characteristic & Treatment \\
\hline Type A1 & $\begin{array}{l}\text { 1) Extensive posterior delamination dividing rotator cuff into } 2 \text { layers, } \\
\text { in full thickness rotator cuff tear } \\
\text { 2) Possible dissociation of rotator cuff cable from cuff posteriorly }\end{array}$ & $\begin{array}{l}\text { 1) Debride delamination } \\
\text { 2) Reduce each layer with appropriate tension and incorporate into } \\
\text { repair } \\
\text { 3) Restore rotator cable }\end{array}$ \\
\hline Type A2 & $\begin{array}{l}\text { 1) Bursal sided partial thickness rotator cuff tear with posterior } \\
\text { delamination }\end{array}$ & $\begin{array}{l}\text { 1) Debride delamination } \\
\text { 2) Reduce bursal sided tear; suture fixation should pass through } \\
\text { delaminated portion and intact articular attachment to minimize } \\
\text { tension-length mismatch }\end{array}$ \\
\hline Type B1 & 1) L-shaped bursal layer tear with crescent shape articular layer tear & $\begin{array}{l}\text { 1) Debride delamination } \\
\text { 2) Repair longitudinal bursal split with side to side repair }\end{array}$ \\
\hline Type B2 & $\begin{array}{l}\text { 1) High grade partial articular sided tear with extensive posterior } \\
\text { delamination }\end{array}$ & $\begin{array}{l}\text { 1) Use suture marking technique to identify area of delamination } \\
\text { subacromially } \\
\text { 2) Convert to type B1 }\end{array}$ \\
\hline Type C & $\begin{array}{l}\text { 1) Extensive degeneration with multiple longitudinal splits, in addition } \\
\text { to horizontal delamination }\end{array}$ & $\begin{array}{l}\text { 1) Complete tear from bursal side at area of extensive degeneration at } \\
\text { most lateral margin of the footprint } \\
\text { 2) Debride and removal non-viable tissue } \\
\text { 3) Debride delaminated area } \\
\text { 4) Suture and incorporate adjacent healthy tissue into repair construct }\end{array}$ \\
\hline
\end{tabular}

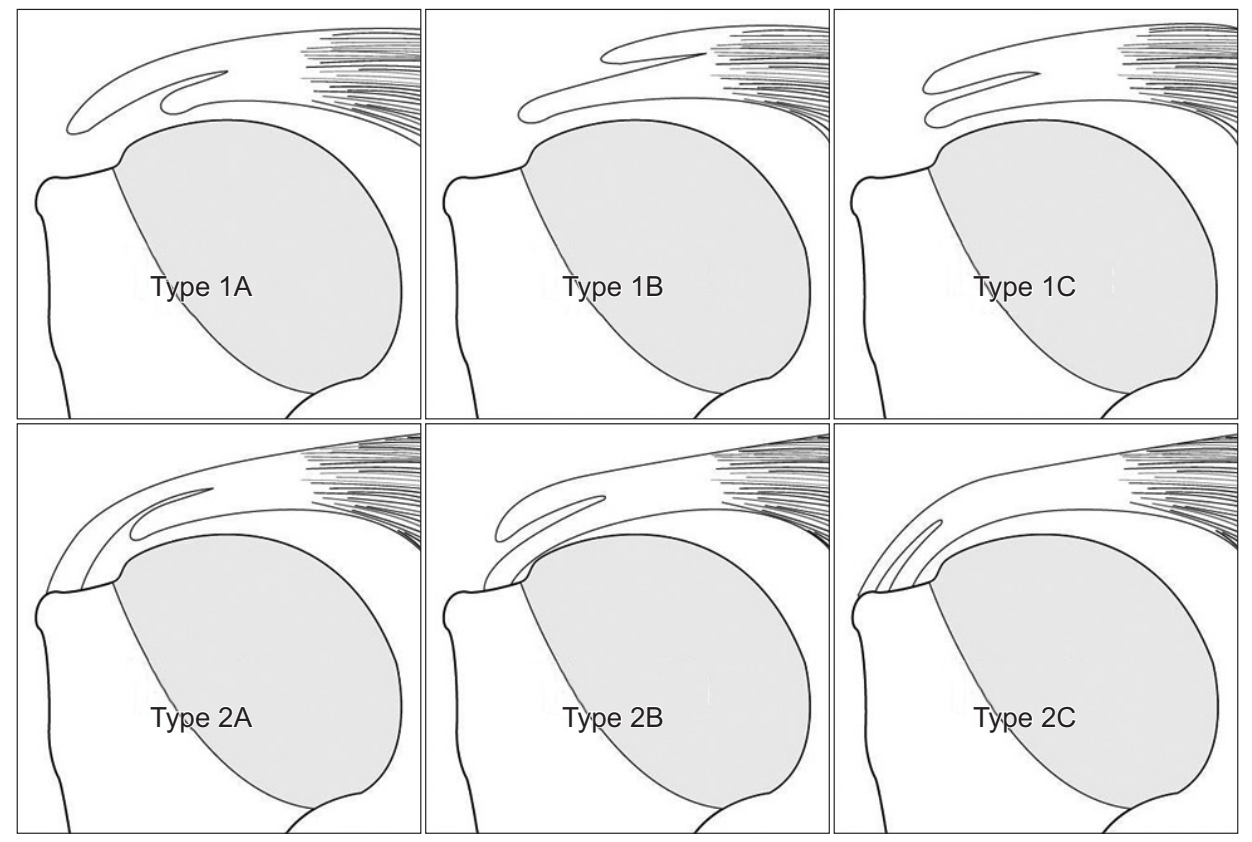

Fig. 2. Figures showing shoulders in oblique coronal plane, representing the six types of delaminated tears at the supraspinatusinfraspinatus tendons. Data from the article of Choo et al. (AJR Am J Roentgenol. 2015;204(2):360-6). . $^{35}$ 
occurring at different time points.

Few studies have considered the thickness of each layer. However, authors report differing thicknesses of articular and bursal layers. Matsuki et al. ${ }^{33)}$ also reported that the deep layer was thicker than the superficial layer in delaminated rotator cuff tear. Tanaka et al. ${ }^{34)}$ noted that larger the size of the rotator cuff tear, the cases frequently revealed a thicker deep layer than the superficial layer; i.e., the deep layer in the large and massive tears was more frequently thicker than superficial layers, in comparison with the small and medium tears. They suggested this may be related to the histologic differences between the two layers. Since the superficial layer atrophies in large and massive cuff tears, the deep layer (that mainly contain the joint capsule comprising collagenous matrix lacking cell bodies) could maintain the thickness without any atrophy. Han et al. ${ }^{6)}$ suggested that the retracted articular layer is not retracted as previously believed, but that the rotator calve separates from the cuff and gives this retracted appearance; they therefore indicated that the deep layer is thicker than the superficial layer.

Matsuki et al. ${ }^{33)}$ reported that most delamination occurs proximally and posteriorly. This pattern is also related with anatomic features. The dorsal muscle fibers of the infraspinatus muscle continue into the second (superficial) layer of supraspinatus muscle, while the ventral fibers of the infraspinatus muscle continue into the third (deep) layer of the supraspinatus muscle. Such anatomic characteristics of the infraspinatus may affect the progress of direction of delamination. Cha et al. ${ }^{13)}$ categorized delaminated rotator cuff tear according to the retraction direction of the deep layer and superficial layer. They suggested that deep layer can be classified into posteromedial and anteromedial retraction, and superficial layer into posteromedial retraction, anteromedial retraction, and bilateral retraction. In their speculation, these retraction patterns may be affected by the infraspinatus, and are important in selecting the optimal surgical technique for anatomic repair with minimal tension, when repairing delaminated rotator cuff tendon.

\section{Classification}

Literature only has a single study for the treatment-based classification system for posterior delamination in rotator cuff tear. Han et al. ${ }^{6)}$ Classified delaminated tear into types A1 to C. Type
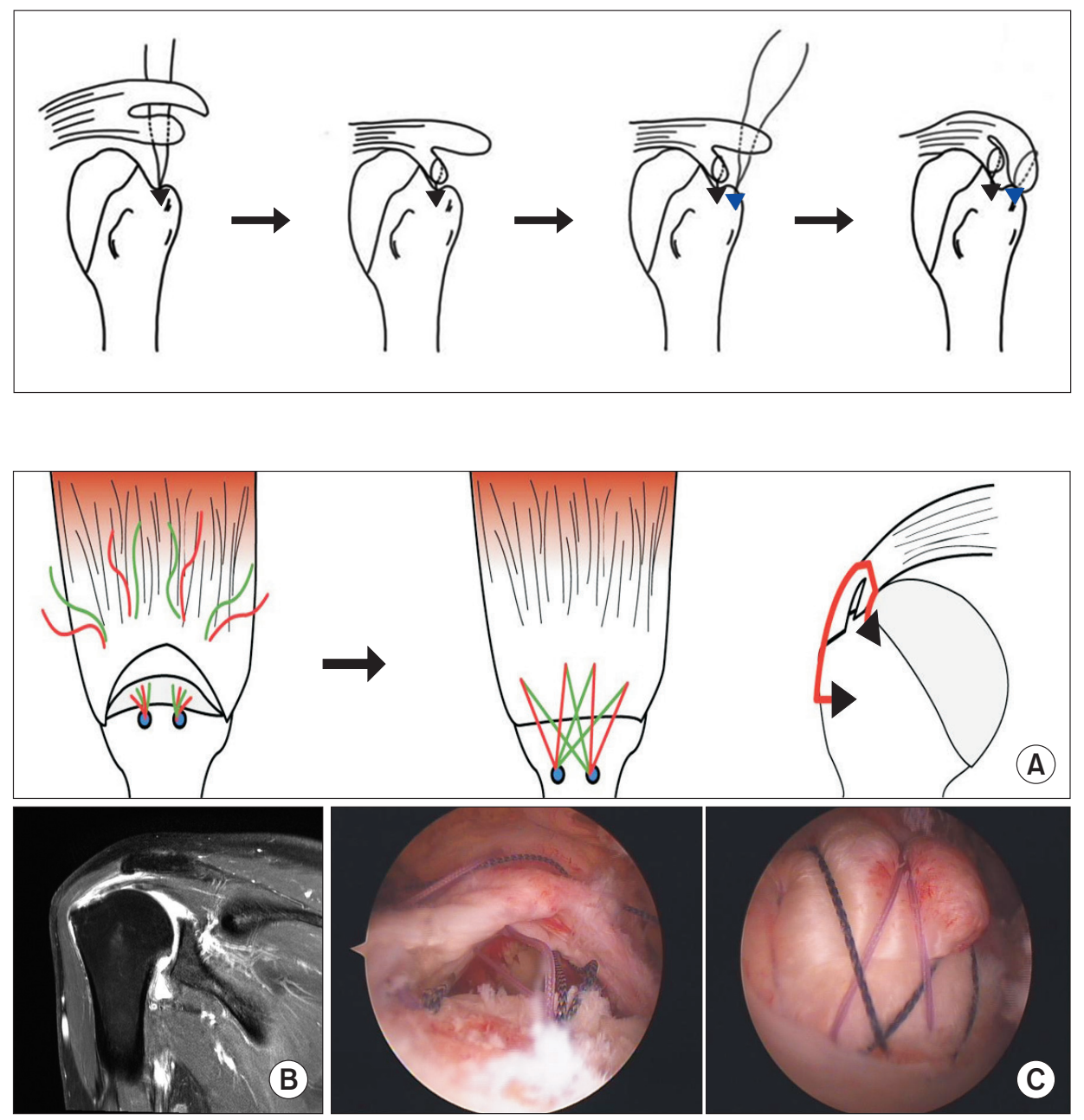

Fig. 3. Surgical repair of delaminated rotator cuff tear using the double-row repair technique. For separate double layer double row repair, the articular layer is first repaired with medial anchors; the remaining sutures are subsequently passed through the bursal layer and bridged with lateral anchors. Data from the article of Sugaya et al. ( $\mathrm{J}$ Bone Joint Surg Am. 2007;89(5):953-60). ${ }^{20}$

Fig. 4. (A) Surgical repair of delaminated rotator cuff tear using the en masse suture bridge repair technique. (B) Typical delaminated tears in the paracoronal magnetic resonance image. (C) For en masse suture bridging, suture is passed through the entire articular and bursal layers and bridged with lateral anchors. Data from the article of Park et al. (Arthroscopy. 2013;29(2):280-9). ${ }^{19)}$ 
Table 2. Comparison of Clinical And Radiologic Outcomes between En Masse Repair and Separate Double Row Repair Techniques for Delaminated Rotator Cuff Tears

\begin{tabular}{|c|c|c|c|c|c|}
\hline \multirow[t]{2}{*}{ Study (yr) } & \multirow[t]{2}{*}{ Study design } & \multirow[t]{2}{*}{ Age (yr) } & \multirow{2}{*}{$\begin{array}{l}\text { Follow-up } \\
\text { (mo) }\end{array}$} & \multirow{2}{*}{$\begin{array}{l}\text { Clinical outcome } \\
\text { (score) }\end{array}$} & \multirow{2}{*}{$\begin{array}{c}\begin{array}{c}\text { Radiologic outcome MRI } \\
\text { (Sugaya classification) }\end{array} \\
\text { Type }(\%)\end{array}$} \\
\hline & & & & & \\
\hline \multicolumn{6}{|c|}{ Kim et al. $(2016)^{39)}$ En masse repair $(\mathrm{n}=48)$} \\
\hline & Prospective randomized & 65.2 & 25.8 & VAS score & Type 4 \& 5 (17.0) \\
\hline & & & & 6.5 (preoperative) & \\
\hline & & & & 2 (postoperative) & \\
\hline & & & & ASES score & \\
\hline & & & & 45.3 (preoperative) & \\
\hline & & & & 84.9 (postoperative) & \\
\hline & & & & SST score & \\
\hline & & & & 38.1 (preoperative) & \\
\hline & & & & 79.4 (postoperative) & \\
\hline & & & & Constant score & \\
\hline & & & & 57.7 (preoperative) & \\
\hline & & & & 80.5 (postoperative) & \\
\hline & \multicolumn{5}{|l|}{ Separate double layer double row repair $(n=34)$} \\
\hline & Prospective randomized & 65.6 & 25.9 & VAS score & \\
\hline & & & & 5.7 (preoperative) & Type 4 \& 5 (18.0) \\
\hline & & & & 1.2 (postoperative) & Type 3 (27.0) \\
\hline & & & & ASES score & \\
\hline & & & & 47.9 (preoperative) & \\
\hline & & & & 89.6 (postoperative) & \\
\hline & & & & SST score & \\
\hline & & & & 51.2 (preoperative) & \\
\hline & & & & 66.7 (postoperative) & \\
\hline & & & & Constant score & \\
\hline & & & & 62.7 (preoperative) & \\
\hline & & & & 84.5 (postoperative) & \\
\hline \multirow{10}{*}{$\begin{array}{l}\text { Nakamizo and } \\
\text { Horie }(2018)^{40)}\end{array}$} & En masse repair $(n=52)$ & & & & \\
\hline & Retrospective & 65.8 & 29 & VAS score & Type 4 or 5 (13.5) \\
\hline & & & & 52.6 (preoperative) & \\
\hline & & & & 13.4 (postoperative) & \\
\hline & & & & SST score & \\
\hline & & & & 4.1 (preoperative) & \\
\hline & & & & 9.5 (postoperative) & \\
\hline & & & & UCLA score & \\
\hline & & & & 13.7 (preoperative) & \\
\hline & & & & 32 (postoperative) & \\
\hline
\end{tabular}




\begin{tabular}{|c|c|c|c|c|c|}
\hline \multirow[t]{2}{*}{ Study (yr) } & \multirow[t]{2}{*}{ Study design } & \multirow[t]{2}{*}{ Age (yr) } & \multirow[t]{2}{*}{$\begin{array}{l}\text { Follow-up } \\
\text { (mo) }\end{array}$} & \multirow[t]{2}{*}{$\begin{array}{l}\text { Clinical outcome } \\
\text { (score) }\end{array}$} & \multirow{2}{*}{$\begin{array}{c}\text { Radiologic outcome MRI } \\
\text { (Sugaya classification) }\end{array}$} \\
\hline & & & & & \\
\hline \multicolumn{6}{|c|}{ Separate double layer double row repair $(n=46)$} \\
\hline & Retrospective & 64.1 & 27.6 & VAS score & Type 4 or 5 (6.5) \\
\hline & & \multicolumn{4}{|c|}{54.1 (preoperative) } \\
\hline & & \multicolumn{4}{|c|}{10.7 (postoperative) } \\
\hline & & \multicolumn{4}{|c|}{ SST score } \\
\hline & & \multicolumn{4}{|c|}{5.1 (preoperative) } \\
\hline & & \multicolumn{4}{|c|}{10 (postoperative) } \\
\hline & & \multicolumn{4}{|c|}{ UCLA score } \\
\hline & & \multicolumn{4}{|c|}{14.8 (preoperative) } \\
\hline & & \multicolumn{4}{|c|}{33.2 (postoperative) } \\
\hline
\end{tabular}

MRI: magnetic resonance imaging, VAS: visual analog scale, ASES: American Shoulder and Elbow Surgeons, SST: Simple Shoulder Test, UCLA: University of California, Los Angeles rating scale.

A1 has extensive delamination which divides the cuff into 2 layers, articular and bursal, and includes the commonly reported lesions, with the articular layer being more "retracted" than the bursal layer. Type A2 lesions also involve posterior delamination, but are bursal sided partial thickness rotator cuff tears. In Type B lesions, more attention is focused on the bursal layer. Type B1 lesion involves an L-shaped tear of the bursal layer and a crescent tear of the articular layer, whereas Type B2 lesions are high grade partial articular side tears with extensive posterior delamination. Type $\mathrm{C}$ lesions are characterized by extensive degeneration, particularly on the bursal side, likely due to impingement with a healthier articular side (Table 1). ${ }^{\text {) }}$

Choo et al. ${ }^{35)}$ classified delaminated rotator cuff tear into 6 types by MRI findings, according to degree of tear (full-thickness or partial-thickness) and retraction degree of each layer (Fig. 2).

\section{Surgical Technique}

Although still controversial, the clinical significance of delamination is the negative prognostic effect on clinical and radiological outcomes. Therefore, many surgical repair techniques have been introduced and are applied to resolve delamination. Sugaya et al. ${ }^{20)}$ repaired deep and superficial layers of delaminated rotator cuff tear to medial and lateral row separately, using the double-row repair technique (Fig. 3). They maintain that each layer of the delaminated rotator cuff tear should be repaired separately, considering that secure fixation of the deep layer to medial footprint area is important for a successful outcome. Mori et al. ${ }^{16)}$ also reported arthroscopic lamina-specific double row fixation for large delaminated rotator cuff tears because they believed that securing repair of the deep layer results in improved tendon healing. Contrarily, Park et al. ${ }^{19)}$ repaired the delaminated rotator cuff tear with an en masse suture bridge repair, with the suture being passed through the entire tendon (Fig. 4). They noted that the en masse suture bridge repair technique unites each layer and decreases the shear force.

\section{Biomechanical and Clinical Study for Repair Technique}

Cheon et al ${ }^{38)}$ compared the histologic healing (at 3 weeks and 6 weeks) and biomechanical characteristics (immediate postoperative; time zero and at 3 weeks) between repair techniques for a delaminated rotator cuff tear in a rabbit model. They reported that two repair techniques (layer by layer and whole layer technique) showed improved histologic healing at 3 weeks and 6 weeks, but the whole layer repair showed a narrow gap between layers and a higher yield load at 3 weeks after operation, compared with the layer by layer technique. They suggested that although patient factors are likely to influence the ability to heal, a surgeon can facilitate optimization of the tendon healing environment by providing a stable repair construct, and noted that a surgical technique that unites the cleft in a delaminated rotator cuff tear could improve the biomechanical strength post-operatively.

Kim et al. ${ }^{39)}$ compared clinical outcomes after delaminated rotator cuff repair between conventional en masse repair and separate double layer double row repair. They report that both repair techniques were effective in improving clinical outcomes, and low pain scores were seen in patients who underwent separate double layer double row repair. However, in their clinical comparison study of en masse versus dual-layer suture bridge 
Clinics in Shoulder and Elbow

Vol. 22, No. 3, September, 2019

Table 3. Clinical and Radiologic Outcomes according to the Rotator Cuff Repair Technique Applied (Review of Previous Literature)

\begin{tabular}{|c|c|c|c|c|c|c|}
\hline Study (yr) & No. of patients & Age (yr) & $\begin{array}{l}\text { Follow-up } \\
\text { (mo) }\end{array}$ & Repair technique & Clinical outcome (score) & Radiologic outcome \\
\hline \multirow[t]{12}{*}{$\begin{array}{l}\text { Opsomer et al. } \\
(2018)^{18)}\end{array}$} & 32 & 63 & 44 & $\begin{array}{l}\text { Arthroscopic double } \\
\text { layer lasso loop } \\
\text { technique }\end{array}$ & Constant score & Ultrasound (\%) \\
\hline & & & & & Healed cuff & \\
\hline & & & & & 53 (preoperative) & Healing (81.0) \\
\hline & & & & & 83 (postoperative) & Partial tear (16.0) \\
\hline & & & & & & Complete re-tear (3.0) \\
\hline & & & & & Partial tear and re-tear & \\
\hline & & & & & 58.7 (preoperative) & \\
\hline & & & & & 74.6 (postoperative) & \\
\hline & & & & & UCLA score & \\
\hline & & & & & Healed cuff & \\
\hline & & & & & 6.4 (preoperative) & \\
\hline & & & & & 9.5 (postoperative) & \\
\hline \multirow[t]{2}{*}{$\begin{array}{l}\text { MacDougal and } \\
\text { Todhunter }(2010)^{10)}\end{array}$} & $\begin{array}{c}105 \\
\text { (delaminated) }\end{array}$ & $\begin{array}{c}59.2 \\
\text { (delaminated) }\end{array}$ & At least 24 & Mini open repair & WORC score & \\
\hline & $\begin{array}{c}43 \\
\text { (non-delaminated) }\end{array}$ & $\begin{array}{c}58.4 \\
\text { (non-delaminated) }\end{array}$ & & & $\begin{array}{l}\text { No difference between } \\
\text { delaminated and } \\
\text { non-delaminated tear }\end{array}$ & \\
\hline \multirow[t]{4}{*}{ Gwak et al. $(2015)^{9)}$} & 65 & 59.9 & 12 & $\begin{array}{l}\text { Arthroscopic en } \\
\text { masse suture bridge } \\
\text { repair }\end{array}$ & No description & 62 cases CTA out of 65 cases \\
\hline & & & & & & $\begin{array}{l}\text { Anatomic healing } \\
\text { (35 cases) }\end{array}$ \\
\hline & & & & & & Partial healing (10 cases) \\
\hline & & & & & & Re-tear (17 cases) \\
\hline \multirow[t]{14}{*}{ Kim et al. $(2016)^{41)}$} & 112 & $\begin{array}{c}61.7 \\
\text { (all layer repair) }\end{array}$ & At least 24 & $\begin{array}{l}\text { Arthroscopic suture } \\
\text { bridge repair (all } \\
\text { layer versus bursal } \\
\text { layer only) }\end{array}$ & VAS score & MRA or CTA \\
\hline & & & & & All layer & All layer \\
\hline & & $\begin{array}{l}60.3 \\
\text { (bursal layer only } \\
\text { repair) }\end{array}$ & & & 6.5 (preoperative) & 57 out of 63 \\
\hline & & & & & 1.2 (postoperative) & Bursal layer only \\
\hline & & & & & Bursal layer only & 45 out of 49 \\
\hline & & & & & 6.4 (preoperative) & Re-tear \\
\hline & & & & & 1.2 (postoperative) & All layer \\
\hline & & & & & SSV score & 16 out of 57 \\
\hline & & & & & All layer & Bursal layer only \\
\hline & & & & & 38.3 (preoperative) & 11 out of 45 \\
\hline & & & & & 89.4 (postoperative) & \\
\hline & & & & & Bursal layer only & \\
\hline & & & & & 38 (preoperative) & \\
\hline & & & & & 90.1 (postoperative) & \\
\hline
\end{tabular}


Delaminated Rotator Cuff Tear: Concurrent Concept and Treatment Jung-Han Kim and Soo-Hwan Jung

Table 3. Continued 1

\begin{tabular}{|c|c|c|c|c|c|c|}
\hline \multirow[t]{8}{*}{ Study (yr) } & No. of patients & Age (yr) & $\begin{array}{l}\text { Follow-up } \\
\text { (mo) }\end{array}$ & Repair technique & Clinical outcome (score) & Radiologic outcome \\
\hline & & & & & \multicolumn{2}{|l|}{ ASES score } \\
\hline & & & & & \multicolumn{2}{|l|}{ All layer } \\
\hline & & & & & \multicolumn{2}{|l|}{36.4 (preoperative) } \\
\hline & & & & & \multicolumn{2}{|l|}{90.4 (postoperative) } \\
\hline & & & & & \multicolumn{2}{|l|}{ Bursal layer only } \\
\hline & & & & & \multicolumn{2}{|l|}{38 (preoperative) } \\
\hline & & & & & \multicolumn{2}{|l|}{90.8 (postoperative) } \\
\hline \multirow[t]{21}{*}{ Kim et al. $(2017)^{36)}$} & 82 & $\begin{array}{c}59 \\
\text { (delaminated) }\end{array}$ & 33.6 & $\begin{array}{l}\text { Arthroscopic en } \\
\text { masse suture bridge } \\
\text { repair }\end{array}$ & VAS score & Delaminated (\%) \\
\hline & & $\begin{array}{c}57 \\
\text { (non-delaminated) }\end{array}$ & & & Delaminated & Anatomic healing (44.9) \\
\hline & & & & & 4.2 (preoperative) & Partially healed (40.8) \\
\hline & & & & & 1 (postoperative) & Re-tear (14.3) \\
\hline & & & & & Non-delaminated & Non-delaminated (\%) \\
\hline & & & & & 3.5 (preoperative) & Anatomic healing (58.7) \\
\hline & & & & & 1.2 (postoperative) & Partially healed (17.4) \\
\hline & & & & & ASES score & Re-tear (12.9) \\
\hline & & & & & \multicolumn{2}{|l|}{ Delaminated } \\
\hline & & & & & \multicolumn{2}{|l|}{54 (preoperative) } \\
\hline & & & & & \multicolumn{2}{|l|}{82 (postoperative) } \\
\hline & & & & & \multicolumn{2}{|l|}{ Non-delaminated } \\
\hline & & & & & \multicolumn{2}{|l|}{56 (preoperative) } \\
\hline & & & & & \multicolumn{2}{|l|}{83 (postoperative) } \\
\hline & & & & & \multicolumn{2}{|l|}{ Constant score } \\
\hline & & & & & \multicolumn{2}{|l|}{ Delaminated } \\
\hline & & & & & \multicolumn{2}{|l|}{57 (preoperative) } \\
\hline & & & & & \multicolumn{2}{|l|}{77 (postoperative) } \\
\hline & & & & & \multicolumn{2}{|l|}{ Non-delaminated } \\
\hline & & & & & \multicolumn{2}{|l|}{55 (preoperative) } \\
\hline & & & & & \multicolumn{2}{|l|}{75 (postoperative) } \\
\hline \multirow[t]{8}{*}{ Kwon et al. (2019) } & 1,042 & $\begin{array}{c}63.3 \\
\text { (delaminated tear) }\end{array}$ & At least 12 & $\begin{array}{l}\text { Arthroscopic single } \\
\text { or double row repair } \\
\text { (suture bridge) }\end{array}$ & VAS score & MRI healing failure (\%) \\
\hline & & $\begin{array}{c}59.0 \\
\text { (non-delaminated) }\end{array}$ & & & & \\
\hline & & & & & Delaminated tear & Delaminated tear (25.2) \\
\hline & & & & & 6.23 (preoperative) & $\begin{array}{l}\text { Non-delaminated tear } \\
(41.0)\end{array}$ \\
\hline & & & & & \multicolumn{2}{|l|}{0.82 (postoperative) } \\
\hline & & & & & \multicolumn{2}{|l|}{ Non-delaminated tear } \\
\hline & & & & & \multicolumn{2}{|l|}{6.19 (preoperative) } \\
\hline & & & & & \multicolumn{2}{|l|}{0.66 (postoperative) } \\
\hline
\end{tabular}


Table 3. Continued 2

\begin{tabular}{|c|c|c|c|c|c|c|}
\hline Study (yr) & No. of patients & Age (yr) & $\begin{array}{l}\text { Follow-up } \\
\text { (mo) }\end{array}$ & Repair technique & Clinical outcome (score) & Radiologic outcome \\
\hline & & \multicolumn{5}{|c|}{ ASES score } \\
\hline & & & \multicolumn{4}{|c|}{ Delaminated tear } \\
\hline & & & \multicolumn{4}{|c|}{47.59 (preoperative) } \\
\hline & & & \multicolumn{4}{|c|}{92.11 (postoperative) } \\
\hline & & & \multicolumn{4}{|c|}{ Non-delaminated tear } \\
\hline & & & \multicolumn{4}{|c|}{47.14 (preoperative) } \\
\hline & & & \multicolumn{4}{|c|}{92.03 (postoperative) } \\
\hline
\end{tabular}

UCLA: University of California, Los Angeles rating scale, WORC: Western Ontario Rotator Cuff Index, CTA: computed tomographic arthrography, VAS: visual analog scale, MRA: magnetic resonance angiography, SSV: subjective shoulder value, ASES: American Shoulder and Elbow Surgeons, MRI: magnetic resonance imaging.

procedure for delaminated rotator cuff tear, Nakamizo and Horie $^{40)}$ reported that both procedures improve the clinical and radiological outcomes, and the dual-layer suture bridge procedure achieved better postoperative range of motion of the shoulder than the en masse procedure (Table 2). ${ }^{39,40)}$

\section{Clinical Outcome}

There is still a controversy whether posterosuperior cuff delamination is a negative prognostic factor for rotator cuff healing and is associated with a high re-tear rate. Boileau et al. ${ }^{8)}$ and Flurin et al. ${ }^{7}$ reported that delaminated rotator cuff tear is a negative prognostic factor. In the recent literature, however, good clinical results have been reported after delaminated rotator cuff repair (Table 3). ${ }^{9,10,18,41,42)}$

Sonnabend and Watson ${ }^{11)}$ studied the structural factors affecting outcomes of rotator cuff repair and suggested that when treated by interlaminar curettage before repair, cuff delamination did not appear to prejudice patient satisfaction. Kim et al. ${ }^{41)}$ also reported that clinical score and range of motion after delaminated rotator cuff tear using suture bridge repair improved significantly. Park et al. ${ }^{19)}$ reported improved clinical outcomes and high healing rate using the en masse suture bridge repair in delaminated rotator cuff tear, and suggested that although delaminated tear might be a negative prognostic factor, it could be solved by surgery.

MacDougal and Todhunter ${ }^{10)}$ compared clinical outcomes between delaminated and non-delaminated rotator cuff tear subsequent to the mini-open technique, and reported that the postoperative score improved significantly in both groups, but the differences were not statistically significant. Kim et al. ${ }^{36}$ and Kwon et al., ${ }^{42)}$ in their comparison study between delaminated and non-delaminated tear groups, suggested that delamination may not be an independent prognostic factor.

\section{Conclusion}

With increasing knowledge on the anatomy of rotator cuff and improved arthroscopic techniques, the incidence of delaminated rotator cuff tear has also risen. Delaminated rotator cuff tear has usually been described as a horizontal split of the tendon substance, and the presence of a delaminated tear is considered a negative prognostic factor for functional and morphologic outcomes after rotator cuff repairs. Even though controversial from which layer of the rotator cuff delamination is initiated, the different strain levels applied across the rotator cuff tendon and shear stress between the bursal and articular layers seem to play a role in its pathogenesis. In delaminated rotator cuff tear, there are differences in the degree and direction of retraction between two layers, and the presence of intrasubstance cleavage. In addition, larger the size of the rotator cuff tear, more frequent is the appearance of delamination; however, this is limited to the posterior region and was frequently encountered in cases where the deep layer is thicker than the superficial layer. Therefore, surgeons need to consider the tear characteristics and carefully evaluate when repairing delaminated rotator cuff tears. Delaminated rotator cuff tears are considered as poor prognostic factors after rotator cuff repair, but many surgical repair techniques have been introduced for resolving this affliction. Recent literatures have reported good clinical results after delaminated rotator cuff repair.

\section{References}

1. Iannotti JP, Deutsch A, Green A, et al. Time to failure after rotator cuff repair: a prospective imaging study. J Bone Joint Surg Am. 2013;95(11):965-71. doi: 10.2106/JBJS.L.00708.

2. Ok HS, Kim BG, Choi WC, Hong CG, Kim JW, Kim JH. Clinical relevance of classifying massive rotator cuff tears: results based on functional and radiological findings after arthroscopic repair. Am J Sports Med. 2017;45(1):157-66. doi: 


\section{$10.1177 / 0363546516667498$.}

3. Ono Y, Dávalos Herrera DA, Woodmass JM, Boorman RS, Thornton GM, Lo IK. Can grafts provide superior tendon healing and clinical outcomes after rotator cuff repairs?: a meta-analysis. Orthop J Sports Med. 2016;4(12):2325967116674191. doi: $10.1177 / 2325967116674191$.

4. Burkhart SS, Hartzler RU. Arthroscopic rotator cuff repair: how to avoid retear. Arthroscopy. 2019;35(1):12-3. doi: 10.1016/j. arthro.2018.11.002.

5. Moezzi D. Editorial commentary: restoration of rotator cuff footprint anatomy is all that matters, no matter how we get there. Arthroscopy. 2018;34(12):3157-8. doi: 10.1016/j.arthro. 2018.08.023.

6. Han Y, Shin JH, Seok CW, Lee CH, Kim SH. Is posterior delamination in arthroscopic rotator cuff repair hidden to the posterior viewing portal? Arthroscopy. 2013;29(11):1740-7. doi: 10.1016/j.arthro.2013.08.021.

7. Flurin PH, Landreau P, Gregory T, et al. Cuff integrity after arthroscopic rotator cuff repair: correlation with clinical results in 576 cases. Arthroscopy. 2007;23(4):340-6. doi: 10.1016/ j.arthro.2007.01.005.

8. Boileau P, Brassart N, Watkinson DJ, Carles M, Hatzidakis AM, Krishnan SG. Arthroscopic repair of full-thickness tears of the supraspinatus: does the tendon really heal? J Bone Joint Surg Am. 2005;87(6):1229-40. doi: 10.2106/JBJS.D.02035.

9. Gwak HC, Kim CW, Kim JH, Choo HJ, Sagong SY, Shin J. Delaminated rotator cuff tear: extension of delamination and cuff integrity after arthroscopic rotator cuff repair. J Shoulder Elbow Surg. 2015;24(5):719-26. doi: 10.1016/j.jse.2014.09.027.

10. MacDougal GA, Todhunter CR. Delamination tearing of the rotator cuff: prospective analysis of the influence of delamination tearing on the outcome of arthroscopically assisted mini open rotator cuff repair. J Shoulder Elbow Surg. 2010;19(7):1063-9. doi: 10.1016/j.jse.2009.12.020.

11. Sonnabend DH, Watson EM. Structural factors affecting the outcome of rotator cuff repair. J Shoulder Elbow Surg. 2002;11(3):212-8. doi: 10.1067/mse.2002.122272.

12. Iwashita S, Hashiguchi H, Okubo A, Yoneda M, Takai S. Characteristics of the patients with delaminated rotator cuff tear. SICOT J. 2018;4:28. doi: 10.1051/sicotj/2018022.

13. Cha SW, Lee CK, Sugaya H, Kim T, Lee SC. Retraction pattern of delaminated rotator cuff tears: dual-layer rotator cuff repair. J Orthop Surg Res. 2016;11(1):75. doi: 10.1186/s13018-0160407-9.

14. Bierry G, Palmer WE. Patterns of tendon retraction in fullthickness rotator cuff tear: comparison of delaminated and nondelaminated tendons. Skeletal Radiol. 2019;48(1):109-17. doi: 10.1007/s00256-018-3013-6.

15. Mochizuki T, Nimura A, Miyamoto T, Koga H, Akita K, Muneta T. Repair of rotator cuff tear with delamination: independent repairs of the infraspinatus and articular capsule. Arthrosc
Tech. 2016;5(5):e1129-34. doi: 10.1016/j.eats.2016.06.004.

16. Mori D, Funakoshi N, Yamashita F. Arthroscopic laminaspecific double-row fixation for large delaminated rotator cuff tears. Arthrosc Tech. 2014;3(6):e667-71. doi: 10.1016/ j.eats.2014.08.004.

17. Kim KC, Rhee KJ, Shin HD, Kim PS. Arthroscopic footprint reconstruction of bursal-side delaminated rotator cuff tears using the suture-bridge technique. Knee Surg Sports Traumatol Arthrosc. 2009;17(7):840-3. doi: 10.1007/s00167-009-07303.

18. Opsomer GJ, Gupta A, Haeni DL, et al. Arthroscopic doublelayer lasso loop technique to repair delaminated rotator cuff tears. Arthroscopy. 2018;34(11):2943-51. doi: 10.1016/j.arthro. 2018.06.024.

19. Park JY, Lhee SH, Oh KS, Moon SG, Hwang JT. Clinical and ultrasonographic outcomes of arthroscopic suture bridge repair for massive rotator cuff tear. Arthroscopy. 2013;29(2):280-9. doi: 10.1016/j.arthro.2012.09.008.

20. Sugaya H, Maeda K, Matsuki K, Moriishi J. Repair integrity and functional outcome after arthroscopic double-row rotator cuff repair. A prospective outcome study. J Bone Joint Surg Am. 2007;89(5):953-60. doi: 10.2106/JBJS.F.00512.

21. Fukuda $\mathrm{H}$. The management of partial-thickness tears of the rotator cuff. J Bone Joint Surg Br. 2003;85(1):3-11.

22. Resnick D. Diagnosis of bone and joint disorders. 4th ed. Philadelphia: Saunders; 2002. 3100-2.

23. Ellman H. Diagnosis and treatment of incomplete rotator cuff tears. Clin Orthop Relat Res. 1990;(254):64-74.

24. Sonnabend DH, Yu Y, Howlett CR, Harper GD, Walsh WR. Laminated tears of the human rotator cuff: a histologic and immunochemical study. J Shoulder Elbow Surg. 2001;10(2):10915. doi: 10.1067/mse.2001.112882.

25. Lee SY, Lee JK. Horizontal component of partial-thickness tears of rotator cuff: imaging characteristics and comparison of $A B E R$ view with oblique coronal view at MR arthrography initial results. Radiology. 2002;224(2):470-6. doi: 10.1148/ radiol.2241011261.

26. Walz DM, Miller TT, Chen S, Hofman J. MR imaging of delamination tears of the rotator cuff tendons. Skeletal Radiol. 2007;36(5):411-6. doi: 10.1007/s00256-006-0265-3.

27. Reilly $\mathrm{P}, \mathrm{Amis} \mathrm{AA}$, Wallace AL, Emery RJ. Mechanical factors in the initiation and propagation of tears of the rotator cuff. Quantification of strains of the supraspinatus tendon in vitro. J Bone Joint Surg Br. 2003;85(4):594-9.

28. Sano H, Wakabayashi I, Itoi E. Stress distribution in the supraspinatus tendon with partial-thickness tears: an analysis using two-dimensional finite element model. J Shoulder Elbow Surg. 2006;15(1):100-5. doi: 10.1016/j.jse.2005.04.003.

29. Kim YS, Kim JM, Bigliani LU, Kim HJ, Jung HW. In vivo strain analysis of the intact supraspinatus tendon by ultrasound speckles tracking imaging. J Orthop Res. 2011;29(12):1931-7. 
doi: 10.1002/jor.21470.

30. Nakajima T, Rokuuma N, Hamada K, Tomatsu T, Fukuda H. Histologic and biomechanical characteristics of the supraspinatus tendon: reference to rotator cuff tearing. J Shoulder Elbow Surg. 1994;3(2):79-87. doi: 10.1016/S1058-2746(09)80114-6.

31. Huang CY, Wang VM, Pawluk RJ, et al. Inhomogeneous mechanical behavior of the human supraspinatus tendon under uniaxial loading. J Orthop Res. 2005;23(4):924-30. doi: 10.1016/j.orthres.2004.02.016.

32. Clark JM, Harryman DT 2nd. Tendons, ligaments, and capsule of the rotator cuff. Gross and microscopic anatomy. J Bone Joint Surg Am. 1992;74(5):713-25.

33. Matsuki K, Murata R, Ochiai N, et al. Histological assessment of delamination observed in rotator cuff tears. Shoulder Jt. 2006;30(3):461-4. doi: 10.11296/katakansetsu1977. 30.3461.

34. Tanaka M, Nimura A, Takahashi N, et al. Location and thickness of delaminated rotator cuff tears: cross-sectional analysis with surgery record review. JSES Open Access. 2018;2(1):8490. doi: 10.1016/j.jses.2017.11.004.

35. Choo HJ, Lee SJ, Kim JH, et al. Delaminated tears of the rotator cuff: prevalence, characteristics, and diagnostic accuracy using indirect MR arthrography. AJR Am J Roentgenol. 2015;204(2):360-6. doi: 10.2214/AJR.14.12555.

36. Kim CW, Kim JH, Gwak HC, Park JH. The comparison of outcomes between delaminated and nondelaminated rotator cuff tear repair: is delamination a negative prognostic factor? J Shoulder Elb Surg. 2017;26(2):216-24. doi: 10.1016/ j.jse.2016.09.015.

37. Zilber S, Carillon Y, Lapner PC, Walch G, Nové-Josserand L. Infraspinatus delamination does not affect supraspinatus tear repair. Clin Orthop Relat Res. 2007;458:63-9. doi: 10.1097/ BLO.0b013e31803b8da7.

38. Cheon SJ, Kim JH, Gwak HC, Kim CW, Kim JK, Park JH. Comparison of histologic healing and biomechanical characteristics between repair techniques for a delaminated rotator cuff tear in rabbits. J Shoulder Elbow Surg. 2017;26(5):838-45. doi: 10.1016/j.jse.2016.10.005.

39. Kim YS, Lee HJ, Jin HK, Kim SE, Lee JW. Conventional en masse repair versus separate double-layer double-row repair for the treatment of delaminated rotator cuff tears. Am J Sports Med. 2016;44(5):1146-52. doi: 10.1177/0363546516628869.

40. Nakamizo H, Horie R. Comparison of en masse versus duallayer suture bridge procedures for delaminated rotator cuff tears. Arthroscopy. 2018;34(12):3150-6. doi: 10.1016/ j.arthro.2018.06.054.

41. Kim SJ, Choi YR, Lee HH, Chun YM. Surgical results of delaminated rotator cuff repair using suture-bridge technique with all-layers or bursal layer-only repair. Am J Sports Med. 2016;44(2):468-73. doi: 10.1177/0363546515615573.

42. Kwon J, Lee YH, Kim SH, Ko JH, Park BK, Oh JH. Delamination does not affect outcomes after arthroscopic rotator cuff repair as compared with nondelaminated rotator cuff tears: a study of 1043 consecutive cases. Am J Sports Med. 2019;47(3):674-81. doi: 10.1177/0363546518817764. 